Portland State University

PDXScholar

Engineering and Technology Management

Faculty Publications and Presentations

$12-1-2017$

\title{
Benchmarking of Technology Roadmapping Process in Energy Sector: A Literature Review
}

Chih-Jen $\mathrm{Yu}$

Portland State University

Tugrul Unsal Daim

Portland State University, tugrul@etm.pdx.edu

Follow this and additional works at: https://pdxscholar.library.pdx.edu/etm_fac

Part of the Engineering Commons

Let us know how access to this document benefits you.

\section{Citation Details}

C. Yu and T. Daim, "Benchmarking of Technology Roadmapping Process in Energy Sector: A Literature Review," 2017 Portland International Conference on Management of Engineering and Technology (PICMET), Portland, OR, 2017, pp. 1-10.

This Article is brought to you for free and open access. It has been accepted for inclusion in Engineering and Technology Management Faculty Publications and Presentations by an authorized administrator of PDXScholar. Please contact us if we can make this document more accessible: pdxscholar@pdx.edu. 


\title{
Benchmarking of Technology Roadmapping Process in Energy Sector: A Literature Review
}

\author{
Chih-Jen Yu, Tugrul Daim \\ Department of Engineering and Technology Management, Portland State University, Portland, Oregon, USA
}

\begin{abstract}
Technology roadmapping (TRM) has been recognized as an effective and flexible technology planning tool to assist company, industry, or nations to layout their strategic technology needs and align their vision and strategic objectives. Technology roadmap have been developed into various types and formats, by means of generic or customized processes, to suit specific organizational requirement in different industry settings such as energy sector. However, evaluating the effectiveness of roadmapping process remains a critical issue for roadmap updating and improvement. This paper proposes a benchmark approach based on a literature review to help develop a comparative model with required checklists.
\end{abstract}

\section{INTRODUCTION}

Technology Roadmapping (TRM) has been widely applied in many industry including energy and utility sectors. [1]-[4] Although several roadmaps have been developed by using energy/utility specific TRM development process, the issue to enhance the robustness and comprehensiveness is deemed as a continuous effort of process improvement. The model in this paper is based on the literature with an expectation of accommodating a more comprehensive viewpoint including generic TRM framework, energy specific TRM process, and TRM critical success factors (CSF). Review of utilities indicates that R\&D portfolio management has been an increasingly important function [5]. Traditional roadmaps from the energy sector [6]-[9] has been demonstrated in the literature. Integration of tools in new sectors have also been a part of the recent literature. [10] Next section will review the relevant literature.

\section{LITERATURE REVIEW}

\section{A. Definition of TRM}

Technology Roadmapping has been reported that it was originated from Motorola in the 1970, and was defined by Bob Galvin, the CEO of Motorola, as "A roadmap is an extended look at the future of a chosen field of inquiry composed from the collective knowledge and imagination of the brightest drivers of change in that field". [11] Garcia \& Bray [12] further articulates that roadmap can be classified as the corporate and industry level, where system requirements, performance targets, technology alternatives and milestones need to be identified. Albright [13] emphasized that roadmap layouts a framework for linking applications, challenges and the technological solutions so as to help set priorities for achieving the objectives. Industry Canada [16], Bernal et al. [17], and UNFCCC [18] also provide some key points of TRM such as meeting future performance targets, alignment of technology investment, and a coherent basis for technology development.

As illustrated in Table 1, these examples of definitions highlight the essence of TRM, including forward-looking, the required collective knowledge, the impelling business drivers, the technology solution and the linkage among these elements. With these key elements integrated and aligned, TRM has been applied in various industry for years and can be regarded as needs-driven technology planning process, whereby technology alternatives can be identified, selected, and developed to satisfy a set of product needs. This process generally involves bringing together a team of experts to provide insights on organizing and presenting this critical technology planning information. As a result of the process, a technology roadmap, the output diagram, can be developed for guiding and facilitating appropriate technology investment decisions.[12]

\section{B. Reasons for TRM and its applications}

According to the Albright Strategy Group [13], there are ten reasons to roadmap, including good planning for a successful product line, explicit element of time for acquiring technology and capability, linking business strategy with technology and product decision, revealing gaps in product and technology plans, prioritizing investments based on drivers, setting more competitive and realistic targets, providing a guide to the team, allowing strategic use of technology across product lines, communicating business, technology and product plans to team members, customers, and suppliers, and building common understanding and shared ownership of the plan. Muran (2015) also adds that roadmaps make business focus on what technology project is needed, optimizing the technology investment, leading to greater alignment based on multi-year priorities, and setting a benchmark against the measurement of success. In short, the major benefits of using TRM may include helping develop a consensus about needs and the technology required to fulfil the needs, providing a mechanism to help experts conduct technology forecasting in targeted areas, and establishing a framework to help plan and coordinate technology developments efforts within a company or across an entire industry. [12] 
TABLE 1: EXAMPLES OF TECHNOLOGY ROADMAP'S DEFINITION

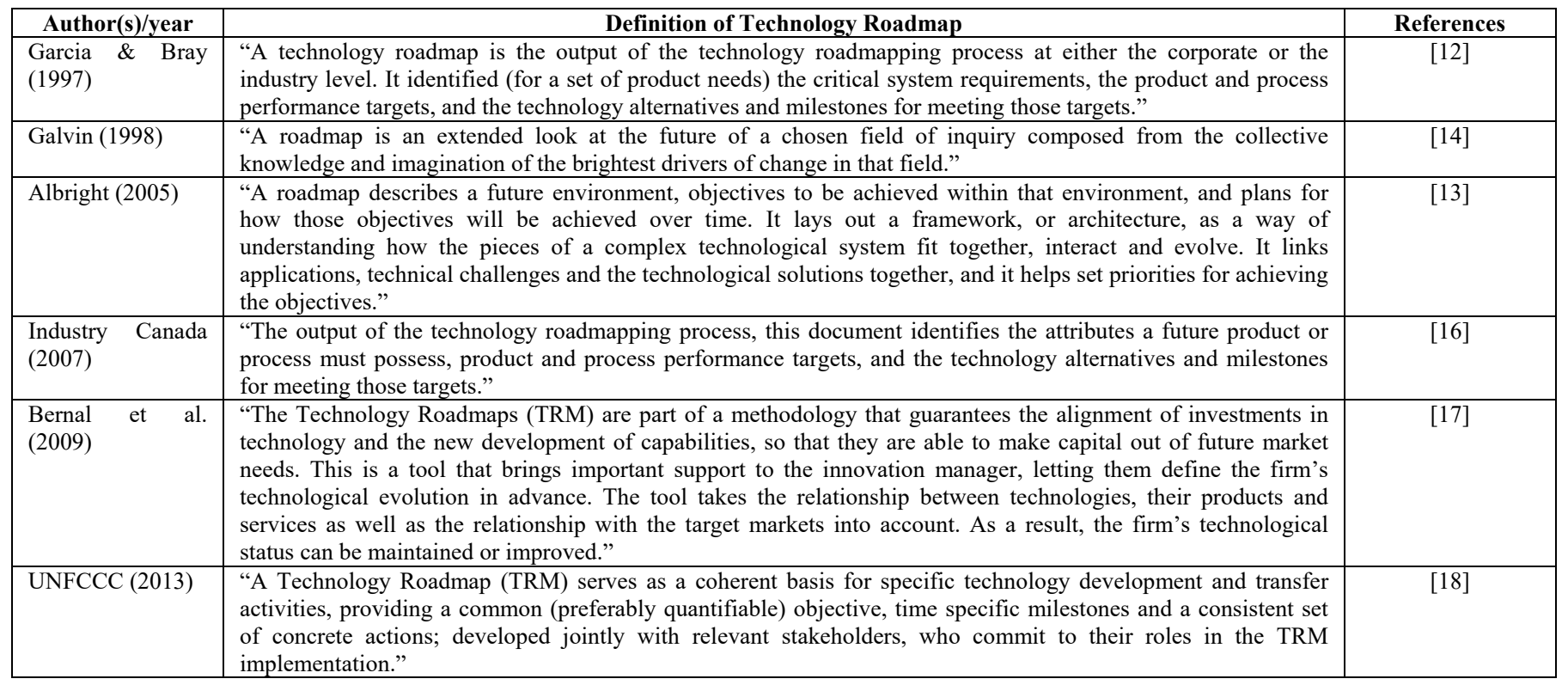

A survey completed in UK for 2000 manufacturing firms shows that $10 \%$ of companies have applied TRM, while about $80 \%$ of those companies either using it once or on an ongoing basis. [19] Another study conducted in Germany during 2015 indicated that the applications for TRM include strategic planning (77.8\%), technology planning (66.7\%), R\&D planning $(61.7 \%)$, product \& services planning $(55.6 \%)$, production planning $(24.7 \%)$, trend monitoring $(24.7 \%)$, market observation $(19.8 \%)$, and others $(6.2 \%)$, based on 81 out of 156 responses. Among these respondents, the sectors involving in implementing TRM include mechanical \& plant engineering (28.4\%), supplier (17.3\%), automotive industry (11.1\%), ICT (4.9\%), consumer goods $(2.5 \%)$, services $(2.5 \%)$, process technology $(1.2 \%)$, other $(11.1 \%)$, and no indication (21.0\%). [20] These survey finding highlights TRM's flexibility of application and wide adoption in industry to support strategic technology planning.[19]

\section{Classification of TRM}

As seen from its substantial applications, the TRM has been developed into various formats to suit different purposes. The classification, or so called typology or taxonomy have been proposed to guide readers to understand the nature and content of technology roadmap from different perspectives.[21] Garcia and Bray [12] claims that TRM include three different types of roadmap, including "Product technology roadmap", "Emerging technology roadmap", and "Issue-oriented roadmap", depending upon different focuses. Kappel [22] presents a roadmapping taxonomy containing four different roadmaps to differentiate and contrast the various purposes and emphasis. His proposition includes "Science/Technology roadmap", "Product - Technology Roadmap" "Industry Roadmap", and "Product Roadmap". By focusing on TRM's domain of application and objective, Kostoff and Schaller [23] proposed to classify roadmaps into "S\&T maps", "Industry technology roadmaps", "Corporate or product - technology roadmaps", and "Product/portfolio management roadmaps".

Later, Phaal R. et al. [19] provide different views of classification for TRM, with focusing on purposes and formats. For purposes, eight types of roadmap have been identified, such as product planning, service/capability planning, strategic planning, long range planning, knowledge asset planning, program planning, process planning, and integration planning. In terms of formats, there are also eight types of roadmaps including multiple layers, bars, tables, graphs, pictorial representations, flow charts, single layer, and text. Lee \& Park [21] add attributes of time frame and information source to be mapped with product and technology to classify roadmap. They proposed eight roadmaps including Product family map, driver map, planning roadmap, and evolution roadmap, as well as Technology portfolio map, position map, prospect roadmap, and trend roadmap. These different classifications of TRM reflect the various applications adopted in industry, which may be attributed to lack of common standards and protocols.[19] However, it did demonstrate TRM's flexibility and extensive applicability.

\section{TRM development process}

As the format or type of a roadmap may be different, the TRM process also diverges. These roadmaps, serving various purposes, have been demonstrated from its wide range of application in many industries and organizations. More importantly, the TRM development process can be designed to fit some certain needs or specific applications. Garcia and Bray [12] provides a near-generic framework outlining three fundamental phases including preliminary activity, development of the TRM, and follow-up activities. Dixon [24] proposed a four-phases model (Roadmap initiation, Technical needs assessment, Technical response development, and Roadmap implementation) for developing a science and technology roadmap for environmental management. Phaal et 
al. [19] proposed the well-known T-plan process featuring with 4 workshop efforts in combing market drivers, product feature, and technology solutions. Industry Canada [16] and Bernal et al. [17] proposes their processes to focus on technological innovation. Daim \& Oliver [8] and International Energy Agency [25] focus on the TRM implementing process and developing a guideline both in the energy sector. Lee et. al. [26] proposes an integrated service-device-technology roadmap process for smart city development and attaches a comparative summary of various TRM processes proposed by 26 papers. This analysis is conducted by classifying the roadmapping process into "Preliminary activity", "Development of TRM", and "Follow-up activity". As illustrated in Table 2, TRM development process generally consists of several phases and/or implementing steps. Depending upon the scope, scale, or different characteristics, the degree of TRM's process complexity also varies.

\section{E. TRM critical success factors}

Critical Success factors (CSF) can be defined as "the handful of key areas where an organization must perform well on a consistent basis to achieve its mission". [27] It has been applied or utilized to evaluate the status/degree of success in many managerial settings such as organizational design, information technology management, strategic planning, and project management. [28][27][29][30] The concept of CSF also has been found to have practical application in TRM to identify the important factors for successful roadmapping. Lee et al. (2013) even includes the identification of CSF as part of the planning activities associated with a TRM process for smart city development. [26] Corresponding with other CSF applications, understanding and evaluating the key characteristics of successful TRM process is deemed to likely contribute the identification of the strength and weakness of the roadmapping process and facilitate the efforts of continuous improvements.

Having analysed relevant literature, the various key successful factors/characteristics of TRM process are listed in Table 3. Although the factors were viewed from different perspectives or managerial standpoints, these determinants may be classified into three aspects including Organizational, Technical, and Project Management. For Organizational aspect, the factors may include Commitment, Vision, Culture, Stakeholder, Participants, Skills, etc. In terms of Technical aspect, the major factors are Linkage between roadmap and strategic plan, Logical TRM process, Software, Layout and Structure of TRM, Methods and Tools. For the Project Management aspect, the major concern may encompass Milestone, Timeline, Action Plan, Priorities, Training, etc.

TABLE 2: EXAMPLES OF TRM DEVELOPMENT PROCESS AND CHARACTERISTICS

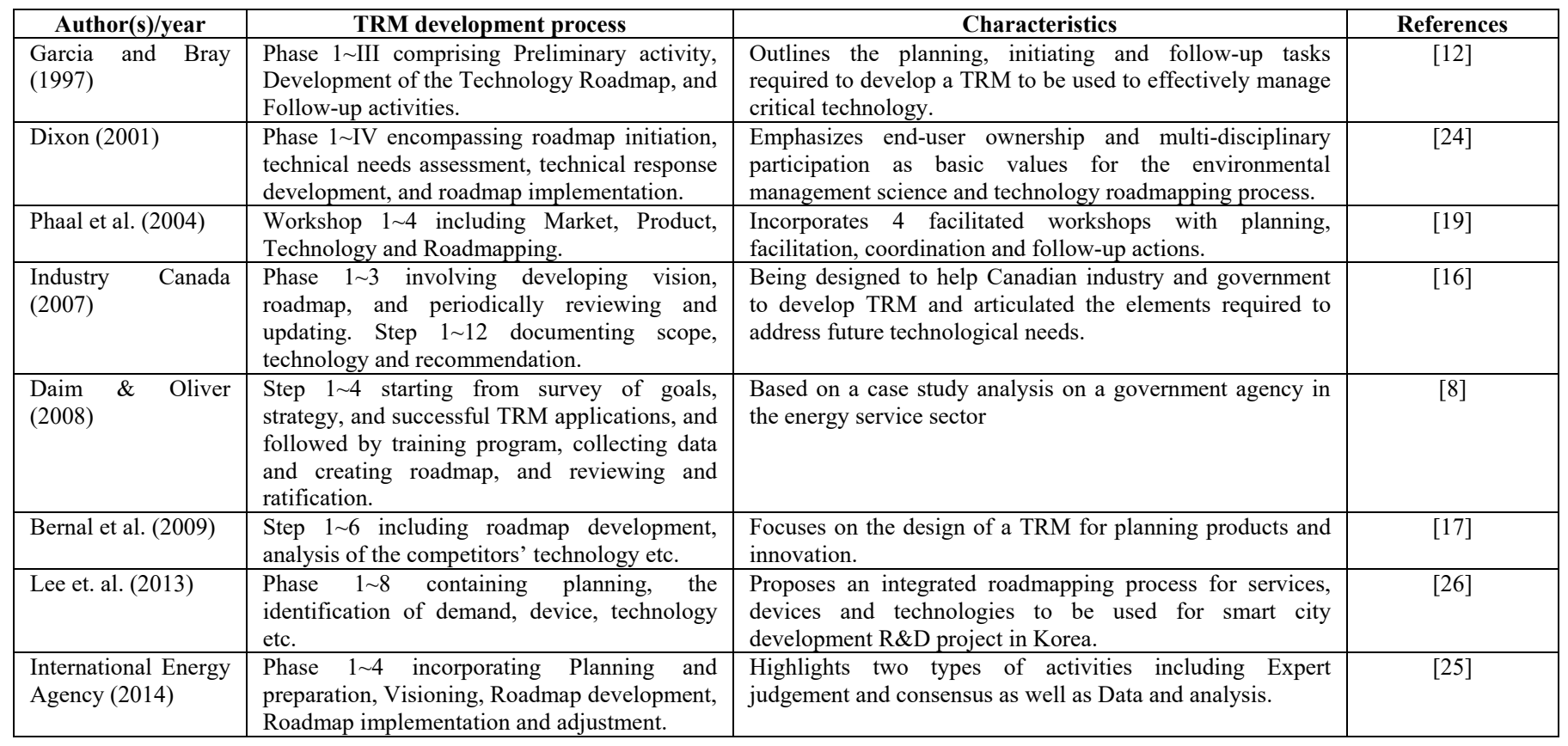


TABLE 3: CRITICAL SUCCESSFUL FACTORS FOR TRM PROCESS

\begin{tabular}{|c|c|c|c|}
\hline Author(s)/year & Critical successful factors & Applications/Sectors & References \\
\hline $\begin{array}{l}\text { Robert Phaal et. al. } \\
\text { (2001) }\end{array}$ & $\begin{array}{l}\text { Clear business need, Desire to develop effective business processes, Company } \\
\text { culture \& politics supported participation/progress, Right people/functions } \\
\text { were involved, Commitment from senior management, Required } \\
\text { data/information/knowledge available, Timing of initiative was appropriate, } \\
\text { Clear and effective process for developing TRM, Effective } \\
\text { tools/techniques/methods, Effective facilitation/training }\end{array}$ & Based on a survey results & [31] \\
\hline $\begin{array}{l}\text { Nathasit Gerdsri et. } \\
\text { al. (2010) }\end{array}$ & $\begin{array}{l}\text { Acceptance of the initiative by key stakeholders, Development of a } \\
\text { customised TRM process, Content quality presented in the roadmap, } \\
\text { Knowledge sharing among different groups of participants, Linkage between } \\
\text { roadmap and corporate strategic plan, Continuation of technology } \\
\text { roadmapping }\end{array}$ & $\begin{array}{l}\text { From the viewpoints of change } \\
\text { management of TRM } \\
\text { implementation }\end{array}$ & [32] \\
\hline $\begin{array}{l}\text { Jung Hoon Lee et. } \\
\text { al. }(2011)\end{array}$ & $\begin{array}{l}\text { Organizational support, Effective roadmap process, Appropriate software, } \\
\text { Alignment with company objective }\end{array}$ & $\begin{array}{l}\text { From the viewpoint of TRM } \\
\text { utilization }\end{array}$ & [33] \\
\hline $\begin{array}{l}\text { Vana } \quad \text { (Evanthia) } \\
\text { Kamtsiou et. al. } \\
(2013)\end{array}$ & $\begin{array}{l}\text { Clear vision, Sufficient and appropriate Skills, Strong enough Incentive, } \\
\text { Sufficient Resources, An appropriate Action Plan }\end{array}$ & $\begin{array}{l}\text { From a context of dynamic } \\
\text { roadmapping }\end{array}$ & [34] \\
\hline $\begin{array}{l}\text { Henry Jeffrey et. al. } \\
\text { (2013) }\end{array}$ & $\begin{array}{l}\text { Having the right people/author in place, Target audience involved as a key } \\
\text { stakeholder in the roadmap's development, Keeping the roadmap "alive", } \\
\text { reviewing and updating it and using it as an open line of communication with } \\
\text { the target audience, Well defined and evenly and effectively addressed target } \\
\text { audience, Clear, defined goals, \& prioritised objectives to avoid trying to do } \\
\text { too much, Effective layout, structure and efficient use of visual graphs and } \\
\text { charts, Focus on clarity and use of concise language, Robust method for } \\
\text { developing the roadmap }\end{array}$ & Renewable Energy Sector & [35] \\
\hline $\begin{array}{l}\text { Ali Bonyadi Naeeni } \\
\text { et. al. (2014) }\end{array}$ & $\begin{array}{l}\text { Commitment from senior management, Selecting the right key players, A } \\
\text { suitable TRM approach (Alignment with vision), Setting TRM process, TRM } \\
\text { software }\end{array}$ & $\begin{array}{l}\text { For emerging technology in } \\
\text { Energy sector }\end{array}$ & [36] \\
\hline IEA (2014) & Goals, Milestones, Gaps and barriers, Action items, Priorities and timelines & Energy Sector & [25] \\
\hline
\end{tabular}

\section{F. Project management best practices}

Based on the TRM development process mentioned above, the whole TRM process can be perceived as a single project or one of the projects within a program, because it is not a routine functional task in an organization/industry. It is a serial of specific and target oriented work involving collaboration across organizational departments, definite scope and timeline for completion, and commitment for providing sufficient resources for implementation. [37] With these natures in places, leveraging project management best practices and its associated tools and techniques seems to play a key role to enhance the effectiveness of TRM development.

Within many project management tools and techniques, the Input-Process-Output (IPO) Model provide a clear and actionable framework of project steps to turn goals and ideas into useful deliverables. The Inputs generally refer to the resources in the form of labor, funding, or data, information, documentation, and other source materials. The Process implying a series of work/tasks done to transform inputs into specific products. The products or so called outputs are basically the results gained through the whole process. [38] In addition, together with this IPO model, some of the proven tools and techniques such as work breakdown structures (WBS), Gantt charts, and responsibility assignment matrices ("RACI diagrams") are deemed to be beneficial for managing a TRM project. These project management best practices has proven effective for planning, implementing, monitoring, and controlling a wide range of projects within and beyond the energy sector. [39] [40]

By applying some of project management best practices and tools such as IPO model, each step can clearly articulate the purpose, required tasks, team assignments, inputs, and outcomes. With WBS and Gantt charts, all tasks can be sequenced, scheduled, and assigned for ease of tracking and monitoring. With Responsibility Assignment Matrix (RAM), project team across organization can be clearly allocated. With some project management information sharing system, the whole TRM process tools and templates can be served as an organizational asset, whereby stakeholders or relevant members can benefit from continuous learning and sustaining TRM knowledge management.

\section{DISCUSSION}

\section{A. In comparison with generic TRM Framework}

As discussed in literature section, the TRM process can be very flexible and customizable to meet specific individual needs. So far, there seems no internationally recognized standard available for developing and implementing TRM process. However, there still exist some common, to some extent, planning or implementing activities among many propositions. Based on the summary table provided from Lee et al. (2013), the major TRM activities in common may include Preliminary activity, Development of the Technology Roadmap, and Follow-up activities. Although the content of each phase varies, the process generally start from planning through development of TRM towards follow-up, monitoring, or updating activities. This three-phase TRM process exactly corresponds to Garcia and Bray's phase classification in their proposed TRM framework.[12] As shown in table 4, the content/steps of Garcia \& Bray's framework is also supported by many literatures. Therefore, Garcia \& Bray's framework was selected as a generic TRM framework for a detailed comparison. 
TABLE 4: GENERIC TRM FRAMEWORK WITH SUPPORTING REFERENCES (ADAPTED FROM GARCIA \& BRAY'S TRM PROCESS)

\begin{tabular}{|c|l|c|}
\hline Phase number & \multicolumn{1}{|c|}{ Activities/steps } & Supporting references \\
\hline Phase I. & Preliminary activity & {$[26][41][42][43]$} \\
\hline & 1.Satisfy essential conditions & {$[44]$} \\
\cline { 2 - 3 } & 2.Provide leadership/sponsorship & {$[26][44]$} \\
\cline { 2 - 3 } & 3.Define the scope and boundaries for the technology roadmap & {$[26][44][25]$} \\
\hline \multirow{5}{*}{ Phase II. } & Development of the Technology Roadmap & {$[26][21][25][43]$} \\
\hline \multirow{5}{*}{} & 1.Identify the product that will be the focus of the roadmap & {$[26][44]$} \\
\cline { 2 - 3 } & 2.Identify the critical system requirements and their targets & {$[44]$} \\
\cline { 2 - 3 } & 3.Specify the major technology areas & {$[26][21][44]$} \\
\cline { 2 - 3 } & 4.Specify the technology drivers and their targets & {$[21][44]$} \\
\cline { 2 - 3 } & 5.Identify technology alternatives and their time lines & {$[45][44]$} \\
\cline { 2 - 3 } & 6.Recommend the technology alternatives that should be pursued & {$[45][44]$} \\
\cline { 2 - 3 } & 7.Create the technology roadmap report & {$[26][21][44]$} \\
\hline \multirow{5}{*}{ Phase III. } & Follow-up activity & {$[26][21][46][47]$} \\
\hline & 1.Critique and validate the roadmap & {$[26][44]$} \\
\cline { 2 - 3 } & 2.Develop an implementation plan & {$[26][44][47][25]$} \\
\cline { 2 - 3 } & 3.Review and update & {$[44][47][48][25][49]$} \\
\hline
\end{tabular}

In order to conduct the TRM framework benchmarking comparison, a check lists/key points associated with Garcia \& Bray's framework are extracted and listed in the table 5. This checklist can be used to differentiate the process and content of the two TRM frameworks.

TABLE 5: TRM CHECK LIST BASED ON GARCIA \& BRAY'S FRAMEWORK

\begin{tabular}{|c|c|c|}
\hline \multicolumn{2}{|c|}{ TRM Framework proposed by Garcia \& Bray [12] } & Checklists/Key points \\
\hline $\begin{array}{l}\text { Phase I. } \\
\text { Preliminary } \\
\text { Activity }\end{array}$ & 1. Satisfy essential conditions & $\begin{array}{l}>\text { A perceived need } \\
>\text { Needs input and participation from different groups } \\
>\text { Needs participation from various parts of the organizations/members of industry } \\
>\text { Needs-driven and a definite scope }\end{array}$ \\
\hline & 2. Provide leadership/sponsorship & $>$ Committed leadership/sponsorship \\
\hline & $\begin{array}{l}\text { 3. Define the scope and boundaries for } \\
\text { the technology roadmap }\end{array}$ & $\begin{array}{l}\text { An existed vision } \\
>\text { A specified scope and boundaries } \\
>\text { Planning horizon and level of detail } \\
>\text { Time horizon }\end{array}$ \\
\hline \multirow{7}{*}{$\begin{array}{l}\text { Phase II. } \\
\text { Development } \\
\text { of the } \\
\text { Technology } \\
\text { Roadmap }\end{array}$} & $\begin{array}{l}\text { 1. Identify the "product" that will be the } \\
\text { focus of the roadmap }\end{array}$ & $\begin{array}{l}>\text { Common product needs } \\
>\text { Scenario-based planning to overcome uncertainty }\end{array}$ \\
\hline & $\begin{array}{l}\text { 2. Identify the critical system } \\
\text { requirements and their targets }\end{array}$ & $\begin{array}{l}>\text { Critical system requirement } \\
>\text { Expected target value }\end{array}$ \\
\hline & 3. Specify the major technology areas & Major technology areas \\
\hline & $\begin{array}{l}\text { 4. Specify the technology drivers and } \\
\text { their targets }\end{array}$ & $\begin{array}{l}>\text { Technology drivers/critical variables } \\
>\text { Technology driver targets }\end{array}$ \\
\hline & $\begin{array}{l}\text { 5. Identify technology alternatives and } \\
\text { their time lines }\end{array}$ & $\begin{array}{l}>\text { Technology alternatives } \\
>\text { Specified time lines for these technology alternatives }\end{array}$ \\
\hline & $\begin{array}{l}\text { 6. Recommend the technology } \\
\text { alternatives that should be pursued }\end{array}$ & $\begin{array}{l}\text { Selecting the subset of the technology alternatives in terms of cost, schedule, and/or } \\
\text { performance }\end{array}$ \\
\hline & 7. Create the technology roadmap report & $\begin{array}{l}\text { The identification and description of each technology area and its current status. } \\
\text { Critical factors (show-stoppers) which if not met will cause the roadmap to fail. } \\
\text { Areas not addressed in the roadmap. } \\
\text { Technical recommendations. } \\
\text { Implementation recommendations. }\end{array}$ \\
\hline \multirow[t]{3}{*}{$\begin{array}{l}\text { Phase III. } \\
\text { Follow-up } \\
\text { Activity }\end{array}$} & 1. Critique and validate the roadmap & $\begin{array}{l}\text { Draft TRM validated by larger group } \\
\text { If the recommended technology alternatives are developed, will the targets be met? } \\
\text { Are the technology alternatives reasonable? } \\
\text { Are any important technologies missed? } \\
>\text { Is the roadmap clear and understandable to people who were not involved in the drafting } \\
\text { process? } \\
>\text { A large, highly structured workshop is used to provide feedback. }\end{array}$ \\
\hline & 2. Develop an implementation plan & $>$ An implementation plan is developed based on the recommended technology alternatives. \\
\hline & 3. Review and update & $\begin{array}{l}\text { Technology roadmaps and plans should be routinely reviewed and updated. } \\
\text { A formal iterative process occurs during this review and update } \\
\text { The review cycle may be based on a company's normal planning cycle or based more } \\
>\text { appropriately on the rate at which the technology is changing. }\end{array}$ \\
\hline
\end{tabular}


By using the above checklist/key points, the associated TRM process and content can be compared and distinguished.

\section{B. In comparison with energy TRM Framework}

As stated in Table 2, for energy-sector-specific TRMs, the International Energy Agency's (IEA) has outlined methods that include two types of activities (Expert Judgement and Consensus; Data and Analysis) and four phases (Planning and Preparation; Visioning; Roadmap Development; Roadmap Implementation and Revision). On average, from phase 1 through 3, it takes about 6 to 18 months to develop a roadmap and followed by phase 4 , which is recurring based and will take 1 to 5 years. [25] This energy roadmap process is depicted in Figure 1 .
- The IEA TRM framework is selected to be the Energy Specific TRM framework for comparison, because IEA is an autonomous agency and includes member countries around the word. Besides, IEA have been devoted in developing roadmaps in energy sector for many years. Again, the check lists/key points are extracted from the content of IEA's TRM guide. Unlike Garcia \& Bray's framework, the IEA's TRM framework does not contain very specific and explicit steps and tasks. For comparison purpose, the sub-title or key points mentioned in IEA's Framework or diagram are assigned numbers, which does not necessarily refer to the sequence of the steps and just make easy to clarify different nature of the related tasks. The checklist is listed in Table 6.

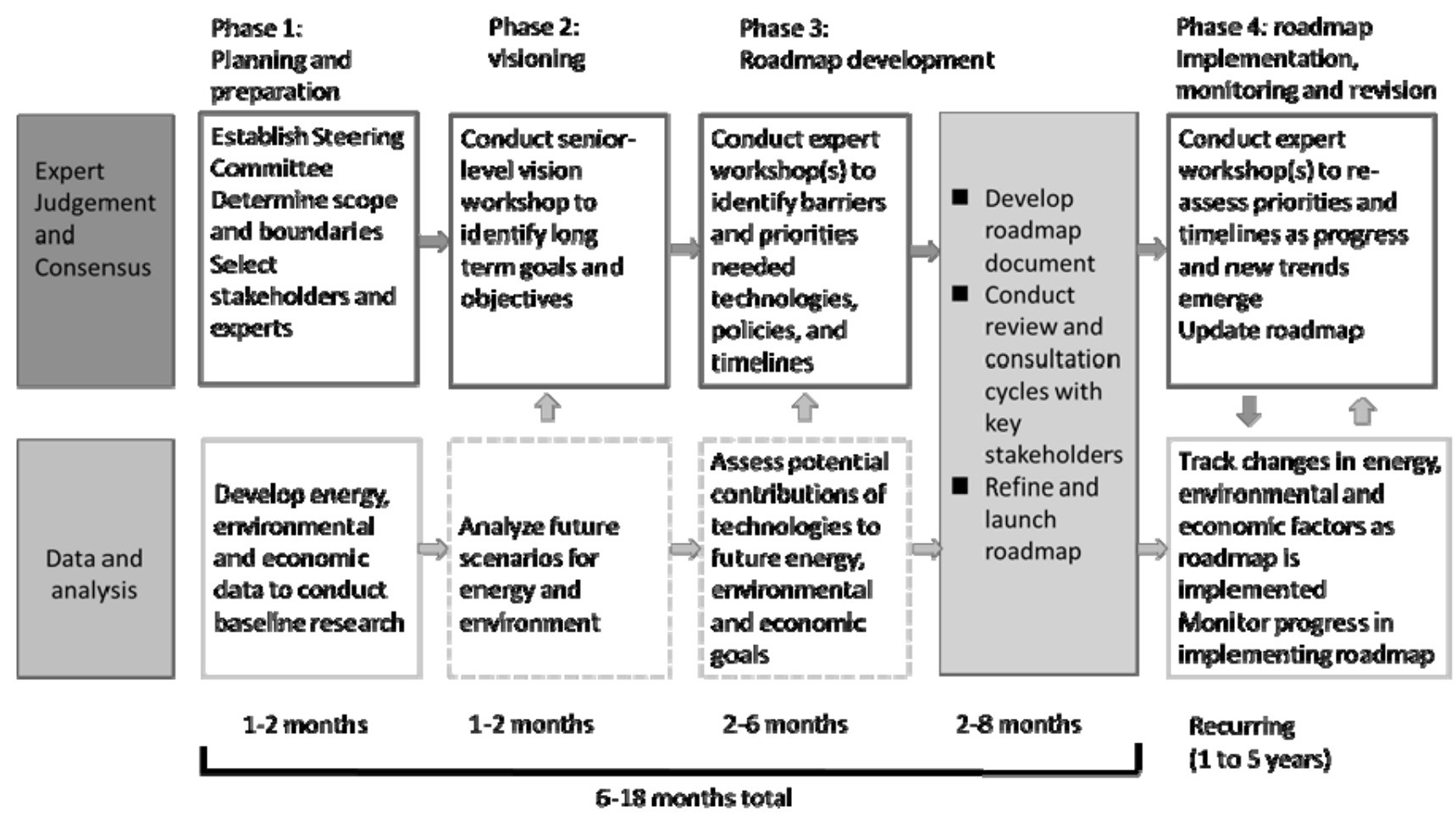

Fig. 1. IEA's energy roadmap process [25] 
TABLE 6: TRM CHECKLIST BASED ON IEA'S FRAMEWORK

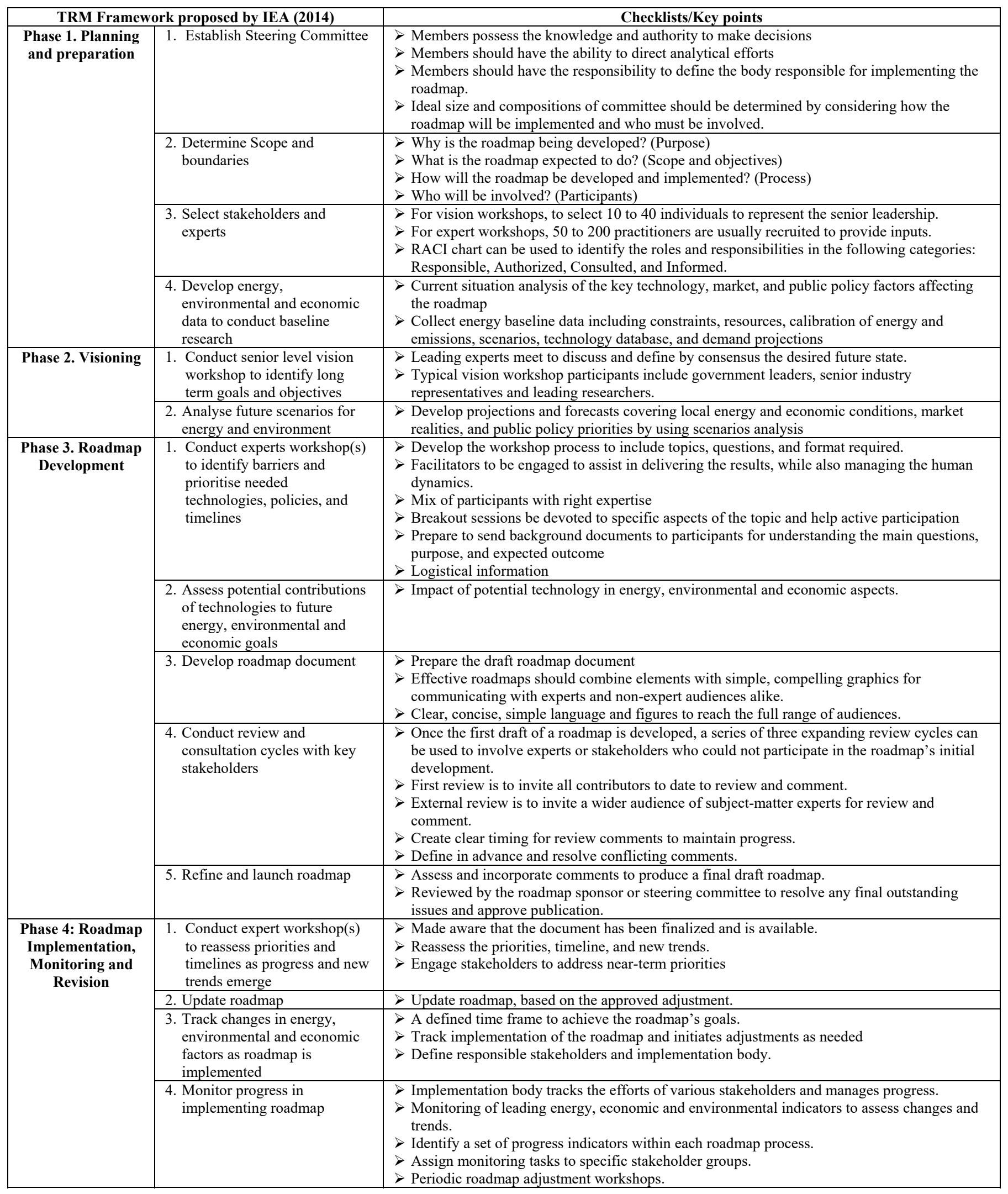


TABLE 7: TRM CHECKLIST BASED ON CRITICAL SUCCESS FACTORS

\begin{tabular}{|c|l|l|c|}
\hline Aspects & \multicolumn{1}{|c|}{ Critical Success Factors } & \multicolumn{1}{c|}{ Checklist } & References \\
\hline Organizational & commitment & $>$ commitment from senior management & {$[36][31]$} \\
\cline { 2 - 4 } & vision & $>$ clear vision & {$[34][36]$} \\
\cline { 2 - 4 } & culture & $>$ supportive culture & {$[31]$} \\
\cline { 2 - 4 } & stakeholder & $>$ target audience as required stakeholder & {$[32][35]$} \\
\cline { 2 - 4 } & participants & $>$ having the right people in place & {$[32]$} \\
\cline { 2 - 4 } & skills & $>$ sufficient and appropriate skills & {$[34]$} \\
\hline \multirow{5}{*}{ Technical } & linkage with roadmap & $>$ linkage between roadmap and strategic plan & {$[32]$} \\
\cline { 2 - 4 } & TRM process & $>$ logical TRM process & {$[32][36]$} \\
\cline { 2 - 4 } & software & $>$ appropriate software & {$[33][36]$} \\
\cline { 2 - 4 } & layout and structure of TRM & $>$ content quality presented in the roadmap & {$[35]$} \\
\cline { 2 - 4 } & methods and tools & $>$ effective methods and tools & {$[35][31]$} \\
\hline \multirow{5}{*}{ Project } & milestone & $>$ set interim performance targets for achieving the goals & {$[25]$} \\
\cline { 2 - 4 } & timeline & $>$ timeframe for important action & {$[25]$} \\
\cline { 2 - 4 } & action plan & $>$ actions that can be taken to overcome any gaps or barriers & {$[34]$} \\
\cline { 2 - 4 } & priorities & $>$ prioritized objective & {$[25]$} \\
\cline { 2 - 4 } & training & $>$ effective training & {$[31]$} \\
\hline
\end{tabular}

\section{In comparison with critical success factors}

As identified in the previous section, the critical success factors for managing TRM process may include Organizational, Technical and Project Management aspects. For comparison purposes, the "success" here is perceived as incorporating a broader scope involving the whole TRM process from the preliminary phase to the follow-up activities. By extracting from those CSF proposed, in organizational aspect, the factors selected for comparison include commitment, vision, culture, stakeholder, participants, skills. For technical aspect, the major factors selected are linkage between roadmap and strategic plan, logical TRM process, software, layout and structure of TRM, methods and tools. For the project management aspect, the chosen factors encompass milestone, timeline, action plan, priorities, and training. The TRM checklist based on these aforementioned critical successful factors is listed in Table 7.

\section{The applicability of TRM checklists}

In view of the importance of the energy technology innovation, several organizations have continuously developed relevant energy technology roadmaps to guide the R\&D efforts or to facilitate technology development towards the energy efficiency or the sustainable energy objective. For example, IEA has published "Solar Photovoltaic Energy", "Energy Storage", "Wind Energy", "Hydropower", and other relevant energy technology roadmaps to demonstrate international consensus on the milestones of these energy technology development.[50]-[53] Electric Power Research Institute used to publish "Electricity Technology Roadmap".[54] International Renewable Energy Agency has been publishing "Roadmap for a Renewable Energy Future" for the past of several years. [55] NASA has issued "Space Power and Energy Storage" in 2015.[56] All these TRM case examples have been developed to suit their specific purposes within the context of the energy sector.

Although these cases may incorporate different formats and unique contents, the development process and tools adopted could impose a critical impact on the overarching TRM effectiveness. As literature review shows, TRM development process is associated with extensive inputs, resources, and organizational support, but also subject to policy, regulation, and other critical successful factors. Therefore, it is important to assure if the process is robust enough for TRM development by using the proposed three TRM checklists. With the key criteria listed in checklists, the target case can be evaluated from general (generic guideline) to specific (energy unique attributes). By reviewing the degree of compliance with these checklists, the performance of specific categories in target case can be articulated, whereby the improvement actions can be initiated accordingly.

\section{CONCLUSIONS AND FUtURE RESEARCH}

TRM has been playing an important role in identifying market drivers, clarifying technology performance/product attributes, and/or guiding R\&D programs for various industries or government agencies. Therefore, it is considered critical to assure the robustness and comprehensiveness of their TRM process in use. By applying the concept of benchmarking, the TRM process can be compared and contrasted to identify its strength and weakness toward continuous improvements.

Review of the literature demonstrates various TRM process in different applications and there are some common critical successful factors associated with their management of TRM process and projects. By using the generic TRM checklist, the target TRM process can be analysed and evaluated to see if it fits or corresponds to the mostly recognized general guideline. By adopting energy specific TRM checklist, the critical elements involving energy, environment, or economic factors can be assessed for meeting required sustainability expectation. For critical successful factor checklist, the target TRM process can be appraised from organizational, technical, and project management perspectives to review its degree of compliance!

Based on literature review and three proposed checklists, the research can be continued to further develop a quantitative mechanism for evaluating TRM in energy sectors and measuring its corresponding equivalency or compliance. A detailed case study is planned to be developed for illustrating the application of these three checklists. This research also can be perceived as a theoretical background study for developing a TRM maturity model aiming to embrace more comprehensive 
benchmark viewpoints and multiple criteria decision making in analysing the degree of TRM maturity level.

\section{REFERENCES}

[1] M. Amer and T. U. Daim, "Application of technology roadmaps for renewable energy sector," Technol. Forecast. Soc. Change, vol. 77, no. 8, pp. 1355-1370, 2010.

[2] K. R. Cowan, "A new roadmapping technique for smart grid," Creat. Innov. Manag., vol. 22, no. 1, pp. 67-83, 2013.

[3] S. K. Lee, G. Mogi, and J. W. Kim, "Energy technology roadmap for the next 10 years: The case of Korea," Energy Policy, vol. 37, no. 2, pp. 588-596, 2009.

[4] W. McDowall, "Technology roadmaps for transition management: The case of hydrogen energy," Technol. Forecast. Soc. Change, vol. 79, no. 3 , pp. 530-542, 2012.

[5] T. U. Daim, T. Oliver, and I. Iskin, "Research and development (R\&D) portfolio management in the electric utility sector: Does it change for the service sector?," Benchmarking An Int. J., vol. 20, no. 2, pp. 186-211, 2013.

[6] J.V Hillegas-elting, C. Yu, T. Oliver, T. Daim, and J. Estep, "Technology Roadmap Development Framework: A Case Study within the Energy Sector," in $R \& D$ Management Conference 2016 "From Science to Society: Innovation and Value Creation," 2016, no. July, pp. $1-14$.

[7] M. Amer, T. U. Daim, and A. Jetter, "Technology roadmap through fuzzy cognitive map-based scenarios: the case of wind energy sector of a developing country," Technol. Anal. Strateg. Manag., vol. 28, no. 2, pp. 131-155, 2016.

[8] T. U. Daim and T. Oliver, "Implementing technology roadmap process in the energy services sector: A case study of a government agency," Technol. Forecast. Soc. Change, vol. 75, no. 5, pp. 687-720, 2008.

[9] T. U. Daim, X. Wang, K. Cowan, and T. Shott, "Technology roadmap for smart electric vehicle-to-grid (V2G) of residential chargers," $J$. Innov. Entrep., vol. 5, no. 1, p. 15, 2016.

[10] C. Hansen, T. Daim, H. Ernst, and C. Herstatt, "The future of rail automation: A scenario-based technology roadmap for the rail automation market," Technol. Forecast. Soc. Change, vol. 110, pp. 196212, 2015.

[11] R. Phaal and D. Oughton, "Roadmapping for strategy and innovation." Center for Technology Management, Institute for Manufacturing, University of Cambridge, UK, pp. 1-7, 2015.

[12] M. L. Garcia and O. H. Bray, "Fundamentals of Technology Roadmapping," Sandia National Laboratories, 1997. [Online]. Available: http://prod.sandia.gov/techlib/accesscontrol.cgi/1997/970665.pdf.

[13] The Albright Strategy Group, "Ten Reasons to Roadmap," 2015. [Online]. Available: http://www.albrightstrategy.com/ten_reasons.html.

[14] R. Galvin, "Science Roadmaps," Science (80-. )., vol. 280, no. 5365, p. 803, 1998.

[15] R. E. Albright, "Roadmapping Convergence," Manag. nano-bio-infocogno Innov., vol. 2003, no. 12, pp. 23-31, 2003.

[16] I. Canada, Technology Roadmapping in Canada: A Development Guide. 2007.

[17] L. Bernal, U. Dornberger, O. Torres, and T. Byrnes, "Technology Roadmapping Handbook," International SEPT Program. Universität Leipzig, pp. 1-17, 2009.

[18] UNFCCC, "Background paper on Technology Roadmaps." Technology Executive Committee of the United Nations Framework Convention on Climate Change, p. 8, 2013.

[19] R. Phaal, C. J. P. Farrukh, and D. R. Probert, "Technology roadmapping-A planning framework for evolution and revolution," Technol. Forecast. Soc. Change, vol. 71, no. 1-2, pp. 5-26, Jan.2004.

[20] S. Schimpf and T.Abele, "Practical Study on Roadmapping." TIM consulting \& Franuhofer IAO, 2016.
[21] S. Lee and Y. Park, "Customization of technology roadmaps according to roadmapping purposes: Overall process and detailed modules," Technol. Forecast. Soc. Change, vol. 72, no. 5, pp. 567-583, 2005.

[22] T. A. Kappel, "Perspectives on roadmaps: How organizations talk about the future," J. Prod. Innov. Manag., vol. 18, no. 1, pp. 39-50, 2001.

[23] R. N. Kostoff and R. R. Schaller, "Science and technology roadmaps," IEEE Trans. Eng. Manag., vol. 48, no. 2, pp. 132-143, 2001.

[24] B. Dixon, "Guidance for Environmental Management Science and Technology Roadmapping," in Waste Management '01 Conference, 2001.

[25] International Energy Agency, "Energy Technology Roadmaps - A guide to development and implementation," 2014.

[26] J. H. Lee, R. Phaal, and S. H. Lee, "An integrated service-devicetechnology roadmap for smart city development," Technol. Forecast. Soc. Change, vol. 80, no. 2, pp. 286-306, 2013.

[27] L. P. Gates, "Strategic Planning with Critical Success Factors and Future Scenarios: An Integrated Strategic Planning Framework," Softw. Eng. Inst., no. November, p. 67, 2010.

[28] R.Pal and H. Torstensson, "Aligning critical success factors to organizational design," Bus. Process Manag., vol. 17, no. 3, pp. 403436, 2011.

[29] M. A. Imtiaz, A. S.Al-Mudhary, M. T.Mirhashemi, and R. Ibrahim, "Critical success factors in information technology projects," Int. J. Soc. Hum. Sci. Eng., vol. 7, no. 12, pp. 1913-1917, 2013.

[30] BMG Research, "Factors in project success. Prepared for: The Association for Project Management (APM)," no. November, p. 68, 2014.

[31] R. Phaal, C. Farrukh, and D. Probert, "Technology Roadmapping: linking technology resources to business objectives," Int. J. Technol. Manag., vol. 26, no. 1, p. 2, 2001.

[32] N. Gerdsri, P. Assakul, and R. S. Vatananan, "An activity guideline for technology roadmapping implementation," Technol. Anal. Strateg. Manag., vol. 22, no. 2, pp. 229-242, 2010.

[33] J. H. Lee, R. Phaal, and C. Lee, "An empirical analysis of the determinants of technology roadmap utilization," $R \& D$ Manag., vol. 41, no. 5, pp. 485-508, 2011.

[34] V. E. Kamtsiou, B. Oliver, M. Derntl, R. Millwood, and A. Naeve, "DYNAMIC ROADMAPPING Managing Innovation in Turbulent Times," 2013.2 [Online]. Available: http://www.telmap.org/sites/default/files/Telmap-Impl-Guide-FinalPrint-3.pdf.

[35] H. Jeffrey, J. Sedgwick, and C. Robinson, "Technology roadmaps: An evaluation of their success in the renewable energy sector," Technol. Forecast. Soc. Change, vol. 80, no. 5, pp. 1015-1027, 2013.

[36] A. B. Naeeni, M. H. Zadeh, M. H. Hemati, and K. Fartash, "The Key Success Factors for Technology Roadmapping for Emerging Technologies in Energy Sector," vol. 3, no. 10, pp. 66-73, 2014.

[37] H. Rafik, Principles of project management. 1982.

[38] J. Zwikael, Ofer, Smyrk, Project Management for the Creation of Organisational Value. Springer-Verlag London, 2011.

[39] National Research Council of the National Academies, Measuring Performance and Benchmarking Project Management at the Department of Energy. 2005.

[40] Project Management Institute, A Guide to the Project Management Body of Knowledge - PMBOK Guide, vol. 44. 2013.

[41] A. M.Lamb, T. U. Daim, and S. Leavengood, "Wood pellet technology roadmap," IEEE Trans. Sustain. Energy, vol. 3, no. 2, pp. 218-230, 2012.

[42] D. Fenwick, T. U. Daim, and N. Gerdsri, "Value Driven Technology Road Mapping (VTRM) process integrating decision making and marketing tools: Case of Internet security technologies," Technol. Forecast. Soc. Change, vol. 76, no. 8, pp. 1055-1077, 2009.

[43] H. Martin and T. U. Daim, "Technology roadmap development process (TRDP) for the service sector: A conceptual framework," Technol. Soc., vol. 34, no. 1, pp. 94-105, 2012. 
[44] S. T. Walsh, "Roadmapping a disruptive technology: A case study: The emerging microsystems and top-down nanosystems industry," Technol. Forecast. Soc. Change, vol. 71, no. 1, pp. 161-185, 2004.

[45] R. N. Kostoff, R. Boylan, and G. R. Simons, "Disruptive technology roadmaps," Technol. Forecast. Soc. Change, vol. 71, no. 1-2, pp. 141$159,2004$.

[46] G. Martin and E. Eggink, "Creation of a thermal technology roadmap in a consumer electronics product environment," Annu. IEEE Semicond. Therm. Meas. Manag. Symp., pp. 106-111, 2008.

[47] S. Lee, S. Kang, Y. Park, and Y. Park, "Technology roadmapping for R\&D planning: The case of the Korean parts and materials industry," Technovation, vol. 27, no. 8, pp. 433-445, 2007.

[48] H. Y. Kim and Y. T. Park, "Development and Application of WebBased Technology Roadmap : QFD and Scenario Planning Approach," in Proceeding of Korean Institute of Industrial Engineeing, 2004.

[49] C. J. Holmes, "A Process for the Update and Review of Operation and Technology Roadmaps," Int. J. Innov. Technol. Manag., vol. 5, pp. 247$258,2008$.
[50] International Energy Agency, "Solar Photovoltaic Energy," Technol. Roadmap, p. 60, 2014.

[51] International Energy Agency, "Technology Roadmap: Energy storage," Energy Technol. Perspect., p. 64, 2014.

[52] International Energy Agency, "Technology roadmap - Wind energy," Technol. Roadmap, p. 58, 2013.

[53] International Energy Agency, "Technology Roadmap. Hydropower," Oecd/Iea, p. 68, 2012.

[54] Electric Power Research Institute, "Electricity Technology Roadmap," EPRI J., vol. 23, no. 6, pp. 24-31, 1998.

[55] International Renewable Energy Agency, "Roadmap For A Renewable Energy Future." 2016.

[56] National Aeronautics and Space Administration, "NASA Technology Roadmaps TA 3: Space Power and Energy Storage," NASA Technology Roadmaps, no. July. 2015. 